\title{
DISPARATE CHANGES IN THE EXPRESSION OF TRANSIENT RECEPTOR POTENTIAL VANILLOID TYPE 1 RECEPTOR MRNA AND PROTEIN IN DORSAL ROOT GANGLION NEURONS FOLLOWING LOCAL CAPSAICIN TREATMENT OF THE SCIATIC NERVE IN THE RAT
}

\author{
C. SZIGETI, ${ }^{\mathrm{a}, \mathrm{b} 1}$ P. SÁNTHA, ${ }^{\mathrm{a} 1}$ E. KÖRTVÉLY, ${ }^{\mathrm{b}}$ T. NYÁRI, ${ }^{\mathrm{c}}$ \\ V. J. HORVÁTH, ${ }^{d}$ É. DEÁK, ${ }^{a}{ }^{M}$. DUX, ${ }^{a}$ \\ K. GULYA ${ }^{b}$ AND G. JANCSÓa* \\ a Department of Physiology, Faculty of Medicine, University of Szeged, \\ H-6720 Szeged, Dóm tér 10, Hungary \\ ${ }^{b}$ Department of Cell Biology and Molecular Medicine, Faculty of Med- \\ icine and Faculty of Science and Informatics, University of Szeged, \\ H-6720 Szeged, Somogyi u. 4, Hungary \\ 'Department of Medical Physics and Informatics, University of Szeged, \\ H-6720 Szeged, Korányi fasor 9, Hungary \\ ${ }^{d}$ Second Department of Internal Medicine, University of Szeged, \\ H-6720 Szeged, Korányi fasor 6, Hungary
}

\begin{abstract}
In situ hybridization, quantitative reverse transcription polymerase chain reaction (RT-PCR), immunohistochemistry, and Western blot analysis were applied to study the changes in expression of the major nociceptive ion channel transient receptor potential vanilloid type 1 receptor (TRPV1) after the perineural application of capsaicin or nerve transection. In control rats, quantitative morphometric and statistical analyses of TRPV1 protein and mRNA expression in L5 dorsal root ganglion cells revealed distinct populations of small (type C) and small-to-medium (type B) neurons, which showed very high and moderate levels of TRPV1, whereas larger (type A) neurons mostly did not express this receptor. After either transection or capsaicin treatment of the sciatic nerve, immunohistochemistry and Western blotting demonstrated a massive (up to $80 \%$ ) decrease in the proportion of TRPV1-immunoreactive neurons and TRPV1 protein at all postoperative survival times. In situ hybridization indicated marked decreases (up to $85 \%$ ) in the proportion of neurons that expressed TRPV1 mRNA after sciatic nerve transection. In contrast, although perineural treatment with capsaicin resulted in similar substantial decreases in the proportions of type $B$ and $C$ neurons of the L5 dorsal root ganglia 3 days postoperatively, a clear-cut tendency to recovery was observed thereafter. Hence, the proportions of both type $B$ and $C$ neurons expressing TRPV1 mRNA reached up to $70 \%$ of the control levels at $\mathbf{3 0}$ days postoperatively. In accord with these findings, quantitative RT-PCR revealed a marked and significant recovery in TRPV1 mRNA after

\footnotetext{
${ }^{1}$ These authors contributed equally to the article.

*Corresponding author. Tel: +36-62-545099; fax: +36-62-545842

E-mail address: jancso@phys.szote.u-szeged.hu or gaborjancso@ yahoo.co.uk (G. Jancsó).

Abbreviations: B2-MG, beta-2-microglobulin; CSA, cross-sectional area; DRG, dorsal root ganglion; GV, gray value; NGF, nerve growth factor; PBS, phosphate buffered saline; ROC, receiver operating characteristic; ROD, relative optical density; RT-PCR, reverse transcription polymerase chain reaction; TBS, Tris-buffered saline; TRPV1, transient receptor potential vanilloid type 1 receptor.
}

perineural capsaicin but not after nerve transection. These observations suggest the involvement of distinct cellular mechanisms in the regulation of the TRPV1 mRNA expression of damaged neurons, specifically triggered by the nature of the injury. The present findings imply that the antinociceptive and anti-inflammatory effects of perineurally applied capsaicin involve distinct changes in neuronal TRPV1 mRNA expression and long-lasting alterations in (post)translational regulation. (c) 2011 IBRO. Published by Elsevier Ltd. All rights reserved.

Key words: capsaicin, perineural, TRPV1 mRNA, pain, nerve transection, in situ hybridization.

Chemosensitive primary sensory neurons, which are sensitive to capsaicin (Jancsó, 1968; Jancsó et al., 1977) and express the transient receptor potential vanilloid type 1 receptor (TRPV1) (Caterina et al., 1997; Caterina and Julius, 2001), play a fundamental role in pain mechanisms. By virtue of their dual functional character, these particular nociceptive neurons comprise a unique population of primary afferent neurons, which transmit impulses generated by noxious stimuli and release neuropeptides from their peripheral and central terminals in response to stimulation (Maggi and Meli, 1988; Holzer, 1991; Jancsó, 2009). The chemosensitive primary afferent neurons, which are selectively sensitive to the stimulatory and neurotoxic effects of capsaicin, account for around $50 \%$ of the dorsal root ganglion (DRG) cells and $95 \%$ of the unmyelinated dorsal root fibers in the rat (Jancsó et al., 1977, 2011; Nagy and Hunt, 1983). Previous studies have demonstrated that selective elimination of these nociceptive afferents either from the whole animal or from selected regions of the body by the systemic (neonatal) or localized (perineural) administration of capsaicin and related vanilloids leads to profound antinociceptive and anti-inflammatory effects (Jancsó et al., 1977, 1980; Fitzgerald and Woolf, 1982; Gamse et al., 1982). The perineural application of vanilloid compounds that results in highly selective regional thermal and chemical analgesia has attracted much interest because of the promising therapeutic relevance of this intervention. Local application of capsaicin or resiniferatoxin has been shown to induce long-lasting increases in the thresholds of nociceptive responses elicited by chemical irritants and intense heat stimuli (Jancsó et al., 1980; Gamse et al., 1982; Chung et al., 1985; Kissin et al., 2002). Local treatment with capsaicin or resiniferatoxin also reduces inflammatory 
thermal and mechanical hyperalgesia and ischemic reactive hyperemia (Kissin et al., 2002; Domoki et al., 2003; Pospisilova and Palecek, 2006; Holzer, 2008; Jancsó et al., 2008; Oszlács et al., 2009) and arthritis (Donaldson et al., 1995). Antidromic vasodilatation and neurogenic inflammation, the cardinal local vascular responses of chemosensitive afferent endings brought about through stimulation with chemical irritants or antidromic stimulation of sensory nerves, are completely abolished by such treatment (Jancsó and Király, 1980; Oszlács et al., 2009). Although the antinociceptive and anti-inflammatory effects of locally applied vanilloid compounds have been repeatedly demonstrated, the mechanisms of these unique antinociceptive/analgesic effects are still unclear. Electrophysiological studies have revealed a selective and long-lasting reduction of impulse conduction in unmyelinated, but not in myelinated sensory axons (Jancsó and Such, 1983; Baranowski et al., 1986; Pini et al., 1990), associated with a reduction of polymodal nociceptor units in rat (Welk et al., 1983; Pini et al., 1990), guinea pig, and rabbit (Baranowski et al., 1986) peripheral nerves. Similar findings have been reported in monkeys following the treatment of peripheral nerves with capsaicin (Chung et al., 1993). Morphological investigations have disclosed a substantial, but partial reduction in the number of unmyelinated sensory (Baranowski et al., 1986; Jancsó and Lawson, 1990), but not autonomic (Jancsó et al., 1987) axons in capsaicin-treated peripheral nerves and in skin areas innervated by a capsaicin-treated peripheral nerve (Jancsó et al., 1980; Dux et al., 1999). Recent findings indicated that the application of resiniferatoxin to peripheral nerves induced lasting analgesia without noticeable fine structural alterations in the rat (Kissin et al., 2002, 2007). Histochemical and immunohistochemical studies have revealed the marked depletion of sensory neuropeptides from the spinal ganglia and the dorsal horn of the spinal cord relating to the peripheral nerve treated with a vanilloid agent (Gamse et al., 1982; Jancsó and Lawson, 1988; Oszlács et al., 2009). However, changes in the expression of the TRPV1, a molecular integrator of nociception (Winter et al., 1988; Caterina et al., 1997; Tominaga et al., 1998), which confers capsaicin (vanilloid) sensitivity on chemosensitive primary afferent neurons (Winter et al., 1988; Caterina et al., 1997; Michael and Priestley, 1999) have not been investigated so far after perineural treatment with vanilloid compounds. The present experiments were therefore initiated in an attempt to make use of in situ hybridization, quantitative reverse transcription polymerase chain reaction (RT-PCR), immunohistochemistry, and Western blot analysis to reveal possible changes in the expression of the TRPV1 following perineural capsaicin treatment and, for comparison, peripheral nerve transection.

\section{EXPERIMENTAL PROCEDURES}

Adult male Wistar rats weighing $240-260 \mathrm{~g}$ at the start of the experiments were used in this study. The animal house was maintained under a 12-h light/dark cycle. All experimental procedures were approved by the Ethical Committee for Animal Care of the University of Szeged and were carried out in accordance with the European Communities Council Directive of 24 November 1986 (86/609/EEC). All efforts were made to minimize the number of animals used and their suffering.

\section{Perineural capsaicin treatment}

The rats were anesthetized with chloral hydrate $(400 \mathrm{mg} / \mathrm{kg}$, i.p., Reanal, Budapest, Hungary). The sciatic nerves were exposed high in the thigh on both sides, and small pieces of gelfoam moistened with $0.1 \mathrm{ml}$ of a $1 \%$ solution of capsaicin (Fluka, Buchs, Switzerland) or the same volume of the vehicle (6\% ethanol, $8 \%$ Tween 80 in saline) were wrapped around the right and left nerves, respectively. After $20 \mathrm{~min}$, the gelfoam pieces were removed, the wounds were closed, and the rats were returned to the animal house. After 3,14 , or 30 days, the animals were again anesthetized and sacrificed for immunohistochemical and in situ hybridization analyses.

\section{Peripheral nerve transection}

The rats were anesthetized with chloral hydrate $(400 \mathrm{mg} / \mathrm{kg}$, i.p., Reanal, Budapest, Hungary). The right sciatic nerve was exposed high in the thigh and transected distal to a ligature. Sham-operated animals served as controls. After 3,14 , or 30 days, the animals were again anesthetized and sacrificed for immunohistochemical and in situ hybridization analyses.

\section{In situ hybridization}

The synthesis of the cRNA probe and in situ hybridization were carried out as described by Maniatis et al. (1982), with slight modifications. To generate TRPV1 mRNA-specific probes, total mRNA was isolated from rat trigeminal ganglia and was reverse transcribed by using the universal dT17-adapter primer (5'GACTCGAGTCGAGTCGACATCGATTTTTTTTTTTTTTTTT -3', M-MuLV reverse transcriptase; Fermentas, Vilnius, Lithuania) according to the manufacturer's recommendations. This cDNA template was used to perform RT-PCR with the following primer combination: forward 5'-AACCATGGAACAACGGGCTAGC-3'; reverse 5'-AACTCGAGTTAGAACAGAGCTGACA-3'. The amplified 255 bp length product was cloned into pcDNA3 vector (Invitrogen, Carlsbad, CA, USA). The identity of the amplified product was confirmed by DNA sequencing and Northern blotting. After linearization of the vectors, sense and antisense digoxigenin-11UTP-labeled cRNA probes were transcribed with T7 or SP6 polymerases, using a DIG RNA labeling kit (Boehringer Mannheim, Mannheim, Germany) according to the manufacturer's protocol.

For in situ hybridization, DRGs were quickly removed, embedded in Cryomatrix embedding material (Shandon Scientific, Pittsburgh, PA, USA), and frozen immediately at $-70{ }^{\circ} \mathrm{C}$. Serial frozen sections of DRGs (15 $\mu \mathrm{m}$ in thickness) were cut on a cryostat and thaw-mounted onto 3-aminopropyltriethoxysilanecoated glass slides. Sections were air-dried and stored at $-20^{\circ} \mathrm{C}$ until further processing. The specimens were fixed for $5 \mathrm{~min}$ in $2 \times$ sodium chloride-sodium citrate (SSC) buffer $(0.3 \mathrm{M} \mathrm{NaCl}$ and 0.03 $\mathrm{M} \mathrm{Na}$-citrate, $\mathrm{pH} 7.0$ ) containing $4 \%$ formaldehyde, washed twice in $2 \times$ SSC buffer for 2 min, permeabilized with $0.1 \%$ Triton X100, washed again as before, and then rinsed in $0.1 \mathrm{M}$ triethanolamine containing $0.25 \%$ acetic anhydride at room temperature for $5 \mathrm{~min}$. Hybridization was performed in $50 \mu$ l hybridization solution $(50 \%$ formamide, $5 \times$ sodium chloride-sodium phosphate-EDTA buffer, $1 \times$ Denhardt's reagent, $10 \%$ dextran sulfate, $50 \mathrm{mM}$ dithiothreitol, $100 \mu \mathrm{g} / \mathrm{ml}$ salmon sperm DNA, and $100 \mu \mathrm{g} / \mathrm{ml}$ yeast tRNA containing $200 \mathrm{nmol} / \mathrm{ml}$ labeled probe) under parafilm cover slips in a humidified chamber at $56{ }^{\circ} \mathrm{C}$ for $20 \mathrm{~h}$. The sections were extensively rinsed in $2 \times \mathrm{SSC}$ buffer supplemented with $50 \%$ formamide at $50{ }^{\circ} \mathrm{C}$ for $15 \mathrm{~min}$, treated with RNase $\mathrm{A}$ at $37^{\circ} \mathrm{C}$ for $30 \mathrm{~min}$, and washed again in $2 \times \mathrm{SSC}-50 \%$ formamide solution at $50^{\circ} \mathrm{C}$. To block nonspecific antibody binding, sections were incubated with 
buffer 1 (100 mM Tris- $\mathrm{HCl}$ and $150 \mathrm{mM} \mathrm{NaCl}, \mathrm{pH}$ 7.5) containing $5 \%$ normal goat serum for $1 \mathrm{~h}$ at room temperature, followed by incubation with alkaline phosphatase-conjugated anti-digoxigenin antibody (1:2500, Boehringer Mannheim GmbH, Mannheim, Germany) in buffer 1 at $4{ }^{\circ} \mathrm{C}$ overnight. Sections were washed in buffer 1 for $3 \times 5 \mathrm{~min}$, rinsed in buffer $2(100 \mathrm{mM}$ Tris- $\mathrm{HCl}, 100 \mathrm{mM}$ $\mathrm{NaCl}$, and $50 \mathrm{mM} \mathrm{MgCl} 2, \mathrm{pH}$ 9.5) for $10 \mathrm{~min}$, and developed in buffer 2 containing $340 \mu \mathrm{g} / \mathrm{ml}$ nitro blue tetrazolium and $180 \mu \mathrm{g} / \mathrm{ml}$ 5-bromo-4-chloro-3-indolyl phosphate for $12 \mathrm{~h}$ in a dark chamber. The reaction was terminated by rinsing the slides in a buffer (10 $\mathrm{mM}$ Tris- $\mathrm{HCl}, 1 \mathrm{mM}$ EDTA, pH 8.0) for $10 \mathrm{~min}$. The sections were covered with glycerol.

\section{Quantitative RT-PCR measurements}

To measure changes in the total TRPV1 mRNA expression in DRGs affected by the transection or capsaicin treatment of the sciatic nerve, quantitative RT-PCR was used. Rats were terminally anesthetized 3,14 , and 30 days after surgery, and the L5 DRGs were excised and transferred into $1 \mathrm{ml}$ ice-cold Trizol reagent (Invitrogen, Carlsbad, CA, USA). Total mRNA was isolated by Trizol solution according to the protocol of the manufacturer. The extracted total mRNA was reverse transcribed by using BioRad iScript cDNA Synthesis Kit (Bio-Rad, Hercules, CA, USA). Specific primers were designed to amplify TRPV1 and beta-2-microglobulin (B2-MG, reference gene) by using the Primer-Blast open source software (http://www.ncbi.nlm.nih.gov/tools/primer-blast). The sequences of the primers were as follows: B2-MG (NM_012512; reference gene): 5'-TCTCCGGTGGATGGCGAGAGT-3' (reverse); 5'-GCTCGCTCGGTGACCGTGATC-3' (forward); TRPV1 (NM_031982.1): 5'TGTCTTCCGGGCAACGTCCA-3' (reverse); 5'-AAGCGCCTGACTGACAGCGA-3' (forward). Primers were synthesized by Integrated DNA Technologies (Leuven, Belgium). These primers produced distinct PCR amplification products with length of $129 \mathrm{bp}$ for TRPV1 and 106 bp for B2-MG, as confirmed by gel-electrophoresis. Quantitative RT-PCR was performed in triplicates utilizing SYBR Green technique (iQ SYBR Green Supermix, Bio-Rad, Hercules, CA, USA) and BioRad MyiQ5 Real Time Detection System running the following amplification protocol: $10 \mathrm{~min}$ on $95^{\circ} \mathrm{C}$ (hot start) followed by 40 amplification cycles (denaturation: $10 \mathrm{~s}$ on $95^{\circ} \mathrm{C}$, annealing: $30 \mathrm{~s}$ on $56^{\circ} \mathrm{C}$; elongation and detection: $20 \mathrm{~s}$ on $72^{\circ} \mathrm{C}$ ). At the end of the amplification, melt-curve analysis was also applied to exclude nonspecific fluorescent signals. Relative quantities of target (TRPV1) mRNAs as compared with the housekeeping reference gene B2-MG were calculated by using the Pfaffl-method (Pfaffl, 2001).

\section{TRPV1 immunohistochemistry}

The animals were deeply anesthetized and perfused transcardially with an aldehyde fixative containing $4 \%$ paraformaldehyde in $0.1 \mathrm{M}$ phosphate buffer ( $\mathrm{pH} 7.4)$. The L5 DRG was removed and postfixed in the same fixative for $2 \mathrm{~h}$ and then placed into a phosphate-buffered $30 \%$ sucrose solution. Representative serial sections of L5 DRGs $15 \mu \mathrm{m}$ in thickness were cut on a cryostat and mounted on gelatin-coated glass slides. Sections were rinsed twice in phosphate-buffered saline (PBS) and incubated overnight with the primary antibody (1:1000; rabbit anti-TRPV1 IgG, ACC030, Alomone Labs, Jerusalem, Israel) with $0.3 \%$ Triton X100 added. After rinsing in PBS, the sections were incubated for $2 \mathrm{~h}$ with the secondary antibody (1:500 biotin-conjugated donkey antirabbit IgG, Jackson ImmunoResearch Laboratories, West Grove, $\mathrm{PA}, \mathrm{USA}$ ) diluted in PBS containing $0.3 \%$ Triton X100. To visualize the biotin-conjugated antibody, the sections were rinsed and treated with the Vectastain ABC Elite staining kit (Vector laboratories, Burlingame, CA, USA) according to the instructions of the manufacturer. The sections were dehydrated and covered with DPX mounting medium (Fluka, Buchs, Switzerland).

\section{Semiquantitative densitometry}

The sections cut from the DRGs and processed for visualization of the TRPV1 mRNA by in situ hybridization or the TRPV1 protein by immunohistochemistry were examined under bright-field illumination with a DMLB microscope (Leica, Wetzlar, Germany) equipped with a Nikon Coolpix (Nikon, Tokyo, Japan) digital camera. Under identical conditions, microphotographs were taken of DRGs relating to control sciatic nerves and sciatic nerves transected or treated perineurally with capsaicin following a systemic random sampling method. The optical density of DRG neurons with clearcut nuclei was measured by means of the NIH Scion Image analysis program. In sections processed for the demonstration of TRPV1 mRNA, many neurons exhibited granular staining of different intensities in the perikaryon. In contrast, in labeled neurons the TRPV1 immunoreactivity displayed diffuse staining throughout the cell bodies and sometimes in their axons. Gray values (GVs) between 0 and 255 were assigned to each neuron with a clearly visible nucleus, and their cross-sectional areas (CSAs) were measured. Relative optical densities (RODs) were determined according to the equation $R O D=\log _{10}(255 /(255-G V))$. The CSA and ROD for each cell were determined and plotted as distribution histograms or scatter plots.

\section{Classification of DRG neurons}

The DRG neurons were classified into different subpopulations by using a statistical approach. Pilot experiments suggested the existence of three distinct neuronal subpopulations in the control DRGs, with different levels of mRNA signal and TRPV1 immunostaining. Discriminant analysis was performed to define the ROD classification effect among the different subpopulations of DRG neurons. To determine the threshold values of ROD for the separation of the neuronal subpopulations, the receiver operating characteristic $(\mathrm{ROC})$ method was applied pairwise (Armitage, 2001; Armitage and Colton, 2005).

\section{Western blot analysis}

L5 DRGs were removed from rats 3, 14, and 30 days after perineural capsaicin treatment or transection of the sciatic nerves and were homogenized immediately in ice-cold radio immuno precipitation assay (RIPA) buffer containing $50 \mathrm{mM}$ Tris $(\mathrm{pH} 8)$, $150 \mathrm{mM}$ sodium chloride, $1 \%$ Triton $\mathrm{X}-100,0.5 \%$ sodium deoxycholate, $0.1 \%$ sodium dodecyl sulfate (SDS), $2 \mu \mathrm{g} / \mathrm{ml}$ leupeptin (Sigma), and $1 \mu \mathrm{g} / \mathrm{ml}$ pepstatin (Sigma-Aldrich, St. Louis, MO, USA). The homogenates were centrifuged at $15000 \mathrm{~g}$ for $10 \mathrm{~min}$. The pellet was discarded, and protein concentrations from the supernatant were determined according to the method of Lowry et al. (1951). Protein samples (60 $\mu \mathrm{g} /$ well) were separated through a $12 \%$ SDS-polyacrylamide gel and transferred to polyvinylidene difluoride (PVDF) membrane (Amersham Biosciences, Little Chalfont, Buckinghamshire, UK) and blocked for $12 \mathrm{~h}$ in $5 \%$ nonfat dry milk in Tris-buffered saline (TBS) containing $0.1 \%$ Tween 20 . The membranes were incubated for $2 \mathrm{~h}$ with rabbit anti-TRPV1 (1:500, Chemicon, Temecula, CA, USA) and mouse anti- $\beta$-actin primary antibody (1:20000, Santa Cruz Biotechnology, Santa Cruz, CA, USA) in $1 \%$ nonfat dry milk in $0.1 \%$ TBS-Tween 20 . After three washes in $0.1 \%$ TBS-Tween 20 , the membranes were incubated for $1 \mathrm{~h}$ with the appropriate peroxidase-conjugated secondary antibodies (1:2000, Jackson ImmunoResearch Europe Ltd., Cambridgeshire, UK), and washed five times as before. The enhanced chemiluminescence method (ECL Plus Western blotting detection reagent; Amersham Biosciences, Little Chalfont, UK) was used to reveal immunoreactive bands according to the manufacturer's protocol. The films were scanned at $600 \times 600 \mathrm{dpi}$ resolution, and the densitometric quantification was performed by the ImageJ public domain image processing and analysis software $(\mathrm{NIH}$, Bethesda, MD, USA). After subtracting background, TRPV1 band 
densities were normalized to $\beta$-actin. The ratio of the TRPV1 to $\beta$-actin band density was used to calculate the changes in TRPV1 expression. Results of three independent experiments are shown as means $\pm S D$.

\section{Statistics}

The experimental data are shown as means \pm SD. Statistical analyses were performed with ANOVA and Holm-Sidak, Brown-Forsythe, or Bonferroni correction methods for post hoc comparisons by using SPSS (v.18, Statistical Software package, IBM Corporation, NY, USA). Differences between groups were considered statistically significant if $P<0.05$.

\section{RESULTS}

\section{Localization of TRPV1 mRNA and protein in the L5 DRG of the rat}

In the control DRGs, three types of neurons could be distinguished with different levels of TRPV1 mRNA expression and TRPV1-immunostaining. Small- to medium-sized neurons displayed intense and moderate expression levels, whereas particularly the larger neurons were mostly devoid of TRPV1 mRNA and protein (Fig. 1A-D). The optimal cut-off point for the TRPV1 mRNA ROD to distinguish between group $C$ and the remaining population was 0.40 , which provided a specificity of $96 \%$ and a sensitivity of $90 \%$. Similarly, a cut-off value of 0.24 provided the optimal differentiation between groups $A$ and $B$ (Fig. 1E, $G)$. Type $C$ and $B$ neurons were characterized by their small (CSA range: $0-400 \mu \mathrm{m}^{2}$ ) and medium sizes (range: 410-900 $\left.\mu \mathrm{m}^{2}\right)$, and high (0.41-1) and moderate (0.25$0.40)$ RODs, respectively. The population of type A neurons was composed of cells of various sizes with low RODs (0-0.24), which hardly exceeded the background ROD. The type $C$ and $B$ neurons were regarded as expressing high and moderate levels of TRPV1 mRNA, whereas type A cells were classified as TRPV1-negative neurons. The in situ hybridization experiments revealed that around half of the DRG cells expressed TRPV1 mRNA in control ganglia. The type $C$ cells accounted for around $19 \%$ and the type B cells approximately $29 \%$ of the total neuronal population. About half $(51 \%)$ of the cells in the DRGs were clearly negative for TRPV1 mRNA. Although the majority of the TRPV1 mRNA-negative neurons were large, some small neurons also exhibited low RODs.

Statistical analysis of the TRPV1-immunopositive neurons revealed three subpopulations of DRG neurons with respect to their TRPV1 protein content (Fig. $1 F, H)$ : the type $C$ and $B$ neurons were mainly small to medium-sized, with strong or moderate staining intensity, respectively, whereas the TRPV1-negative neurons were mostly large.

\section{Effects of perineural capsaicin treatment or transection of the sciatic nerve on the expression of the TRPV1 in the L5 DRG of the rat}

In the rat, the sensory fibers of the sciatic nerve originate from the fourth, the fifth, and (to a much lower extent) the sixth lumbar DRGs (Green, 1968). Up to $85 \%$ of the neurons in the fifth lumbar DRG project their axons into the sciatic nerve (Yip et al., 1984; Aldskogius et al., 1988). In the present study, therefore, the fifth lumbar DRG was chosen to study possible changes in the expression of the TRPV1 following two types of nerve injury: nerve transection, a physical injury resulting in neurotmesis, damage to all types of axons of the sciatic nerve (Seddon, 1943), and perineural treatment with capsaicin, which produces a selective chemodenervation of $\mathrm{C}$-fiber afferents, but leaves the continuity of the nerve intact.

Perineural treatment with capsaicin resulted in a rapid decrease in the expression of TRPV1 mRNA in the neurons of the fifth lumbar DRG, with reductions by about $50 \%$ and $75 \%$ in type $B$ and $C$ cells 3 days after the treatment. However, this initial decrease in TRPV1 expression was followed by a distinct recovery and the proportion of TRPV1 mRNA-expressing neurons gradually increased up to $70 \%$ of the control levels toward the end of the study (Table 1). The experiments using quantitative RT-PCR confirmed these findings by showing an early and marked reduction in TRPV1 mRNA expression already 3 days after perineural capsaicin treatment. However, at later survival times quantitative RT-PCR measurements revealed a clear-cut tendency to recovery toward control expression levels resulting in a marked and statistically significant increase in TRPV1 mRNA at 30 days (Fig. 2A). Study of the localization of the TRPV1 protein by means of immunohistochemistry revealed that the proportion of TRPV1positive ganglion cells had decreased markedly (to about $30 \%$ of the control level) 3 days after perineural capsaicin treatment, and it remained at that low level throughout the entire period of the study (Table 1). The reduction in the proportion of type $\mathrm{C}$ cells was especially pronounced, by about $85 \%$. The analysis of the experimental data clearly showed the time-dependent and cell type-specific changes in the expression of TRPV1 mRNA and protein, respectively (Figs. 3 and 4). Western blot analysis of the TRPV1 protein supported the immunohistochemical findings. The TRPV1 protein was markedly and significantly reduced at all time points after perineural treatment with capsaicin (Fig. 2B, C).

Similarly to perineural treatment with capsaicin, peripheral nerve transection resulted in rapid and marked reductions in both TRPV1 mRNA expression and TRPV1 protein in the type $B$ and $C$ cells of the related fifth lumbar DRG 3 days after surgery. However, in contrast with capsaicin treatment, the TRPV1 mRNA expression did not recover, but remained at a low level for the entire remainder of the study period. In accord with this, the proportion of TRPV1immunoreactive neurons dropped to about $30 \%$ of the control level and then remained low throughout the study. Again, the decreases in TRPV1 mRNA expression and TRPV1 protein (by about $80 \%$ ) were especially marked in the type $C$ cells (Table 1, Fig. 5). In accordance with the results obtained with in situ hybridization, quantitative RTPCR measurements revealed marked and significant reductions in the TRPV1 mRNA expression 3 and 14 days after nerve transection. TRPV1 mRNA expression showed some increase after 30 days, but that did not reach significance (Fig. 2A). 

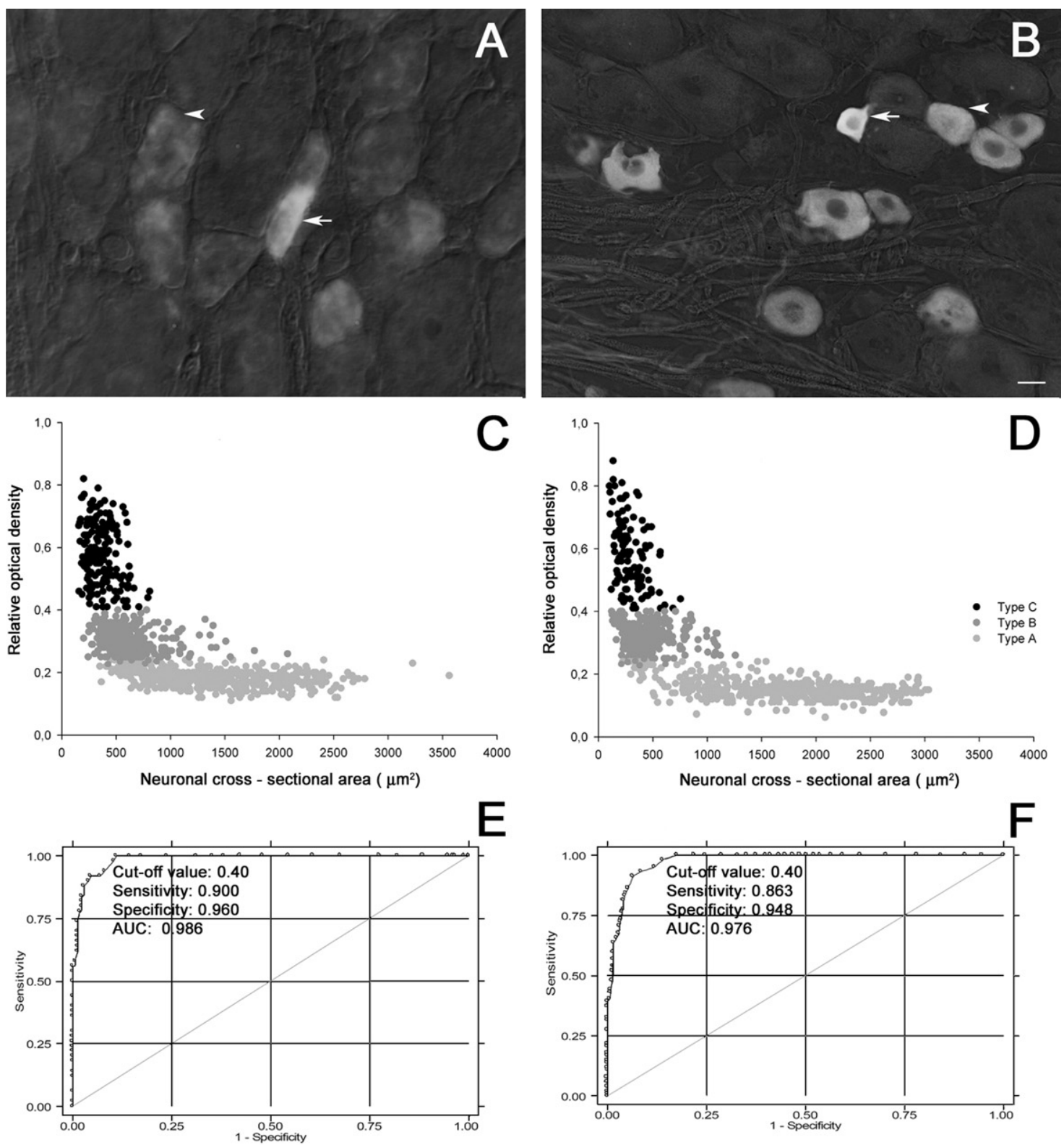

$\mathrm{E}$

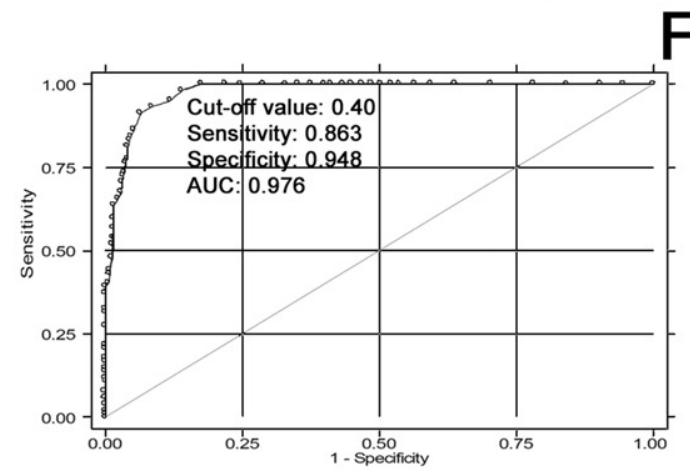

G
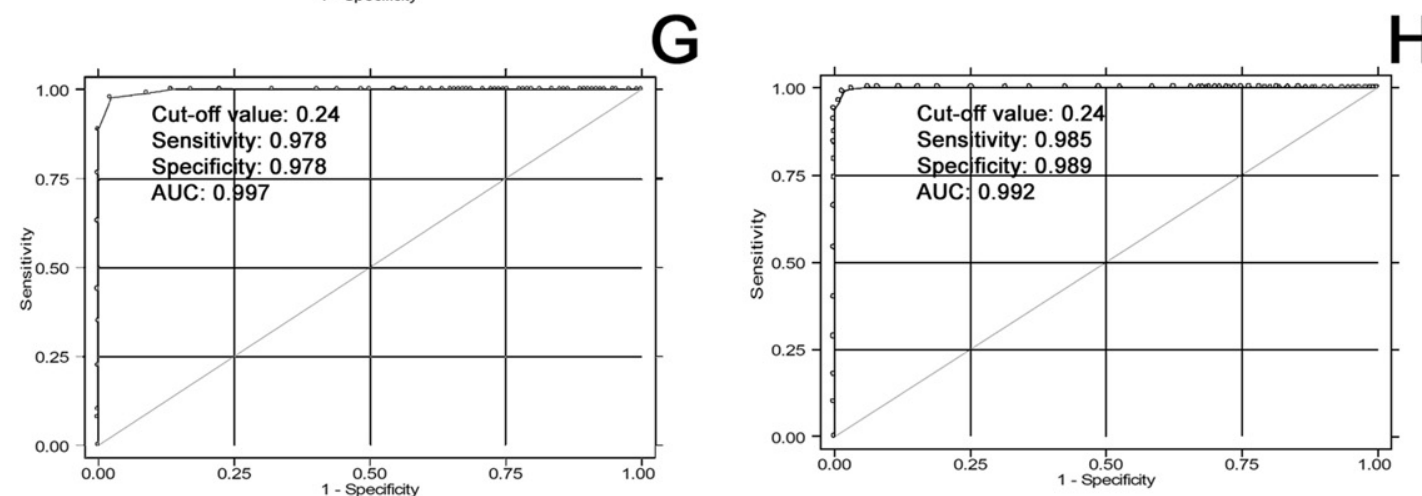

Fig. 1. (A, B) In control ganglia, in situ hybridization (A) and immunohistochemistry (B) revealed small- to medium-sized neurons with intense (arrow) and moderate (arrowhead) levels of TRPV1 mRNA and protein, respectively. Larger neurons were usually devoid of both TRPV1 mRNA and protein. Inverse microphotographs; scale bar indicates $25 \mu \mathrm{m}$. (C, D) Scatter plots of DRG cells, showing the cell sizes and the three separate populations of neurons with intense, moderate, and very low RODs. (E, G) ROC analysis of TRPV1 mRNA RODs revealed the cut-off values for the separation of type $C$ and $B(E)$ and type $B$ and $A(G)$ neurons, respectively, and disclosed the high sensitivity and specificity of the analysis involving the use of ROD. $(F, H)$ ROC analysis of the RODs of TRPV1-immunopositive neurons revealed the cut-off values for the separation of type $C$ and $B(F)$ and type $B$ and $A(H)$ neurons, respectively, and disclosed the high sensitivity and specificity of the analysis using ROD. 
Table 1. Percentage distribution of TRPV1-expressing (type B, C) and TRPV1-negative (type A) L5 DRG neurons 3, 14, and $30 \mathrm{~d}$ after perineural capsaicin treatment and nerve transection

\begin{tabular}{|c|c|c|c|c|c|c|c|c|}
\hline \multirow[t]{2}{*}{ Neuron type } & \multicolumn{4}{|c|}{ TRPV1 mRNA expression } & \multicolumn{4}{|c|}{ TRPV1 immunohistochemistry } \\
\hline & Control & $3 d$ & $14 \mathrm{~d}$ & $30 \mathrm{~d}$ & Control & $3 d$ & $14 \mathrm{~d}$ & $30 \mathrm{~d}$ \\
\hline \multicolumn{9}{|c|}{ Perineural capsaicin } \\
\hline C & $19 \pm 1.28$ & $5 \pm 0.74^{*}$ & $9 \pm 0.62^{\star \#}$ & $12 \pm 1.4^{\star \#}$ & $17 \pm 1.73$ & $2 \pm 0.56^{*}$ & $4 \pm 0.30^{*}$ & $3 \pm 0.43^{*}$ \\
\hline B & $29 \pm 2.33$ & $15 \pm 1.03^{*}$ & $15 \pm 0.91^{*}$ & $20 \pm 1.2^{\star \#}$ & $36 \pm 1.00$ & $9 \pm 2.23^{*}$ & $11 \pm 0.72^{*}$ & $12 \pm 0.82^{*}$ \\
\hline A & $51 \pm 3.13$ & $79 \pm 1.76^{*}$ & $75 \pm 1.51^{*}$ & $69 \pm 4.7^{\star \#}$ & $46 \pm 1.00$ & $89 \pm 2.06^{*}$ & $84 \pm 0.45^{*}$ & $84 \pm 0.44^{*}$ \\
\hline \multicolumn{9}{|c|}{ Nerve transection } \\
\hline C & $18 \pm 1.37$ & $3 \pm 0.36^{*}$ & $2 \pm 0.03^{*}$ & $2 \pm 0.20^{*}$ & $15 \pm 1.73$ & $2 \pm 0.60^{*}$ & $5 \pm 1.03^{*}$ & $4 \pm 0.26^{*}$ \\
\hline $\mathrm{B}$ & $28 \pm 3.10$ & $15 \pm 1.03^{*}$ & $16 \pm 1.72^{*}$ & $16 \pm 1.46^{*}$ & $37 \pm 4.70$ & $16 \pm 1.90^{*}$ & $16 \pm 1.20^{*}$ & $18 \pm 065^{*}$ \\
\hline$A$ & $53 \pm 1.85$ & $82 \pm 1.33^{*}$ & $82 \pm 1.69^{*}$ & $81 \pm 1.26^{*}$ & $50 \pm 0.60$ & $80 \pm 2.35^{*}$ & $78 \pm 0.80^{*}$ & $77 \pm 100^{*}$ \\
\hline
\end{tabular}

Data are expressed as means \pm SD.

* Significantly different from the control, $P<0.05$.

\# Significantly different from the $3 \mathrm{~d}$ value, $P<0.05$.

\section{DISCUSSION}

Chemosensitive primary sensory neurons which express the TRPV1 play a fundamental role in the transmission of nociceptive impulses (Jancsó et al., 1977; Caterina et al., 1997; Julius and Basbaum, 2001). The level of expression of the TRPV1 is an important determinant of the nociceptor function. Increases in TRPV1 mRNA expression and in peripherally directed axonal transport of TRPV1 protein have been demonstrated to be associated with neuropathic pain states and inflammation (Tohda et al., 2001). Conversely, knockdown of the TRPV1 gene prevents the development of inflammatory hyperalgesia in the rat (Caterina et al., 2000; Davis et al., 2000; Kasama et al., 2007). Hence, TRPV1 antagonism or procedures, which inhibit the activation of the receptor may produce significant antinociception. Indeed, the local application of capsaicin and some other vanilloids directly onto peripheral nerve trunks has been shown to provide long-lasting and selective chemical and thermal analgesia, confined to the region innervated by the affected nerve (Jancsó et al., 1980, 2008, 2011; Gamse et al., 1982; Fitzgerald and Woolf, 1982; Kissin et al., 2002; Knotkova et al., 2008). Despite numerous investigations that have made use of perineural capsaicin treatment (Gamse et al., 1982; Gibson et al., 1982; Chung et al., 1985; Jancsó and Lawson, 1987, 1990; Jancsó et al., 1987; Pini et al., 1990; Jancsó and Ambrus, 1994; Kissin et al., 2002), the mechanism of analgesia induced by perineural capsaicin remained unclear.

In the present study, the cell size and the ROD of the mRNA signal and the immunostaining were measured, and a statistical approach was applied to classify subpopulations of DRG neurons which express the TRPV1. In agreement with the findings of a previous radioactive in situ hybridization study (Michael and Priestley, 1999), the present findings revealed two subpopulations of small- and medium-sized neurons that exhibited moderate and high intensities of TRPV1 mRNA expression and TRPV1 immunoreactivity. The two populations of DRG neurons that expressed TRPV1 mRNA or TRPV1 protein could be clearly distinguished through a statistical approach involving ROC analysis based on two characteristic traits of
TRPV1-positive neurons: the cell size and the ROD of the mRNA signal or the immunostaining for TRPV1. The quantitative data demonstrated that a distinct subpopulation of small DRG neurons displayed a significantly higher TRPV1 mRNA expression than did a larger population of smalland medium-sized TRPV1-expressing neurons, which accounted for around $19 \%$ and $30 \%$ of the total neuronal population, respectively, in the L5 DRGs of the rat.

The main finding of the present study is the demonstration of disparate changes in the expression of TRPV1 mRNA and protein in DRG neurons after selective chemical denervation by perineural capsaicin treatment. Further, the findings also indicate differences in the regulation of TRPV1 expression following selective chemical and physical injuries inflicted upon primary sensory neurons.

In accord with previous reports, peripheral nerve transection resulted in a substantial reduction in the proportion of TRPV1 mRNA-expressing neurons, which was already evident 3 days after surgery and persisted for at least 4 weeks in the L5 DRGs. This was closely paralleled by a significant and persistent decrease in the proportions of TRPV1-immunoreactive neurons in the L5 DRGs. These findings corroborate and extend previous reports of parallel reductions in TRPV1 mRNA expression and protein level in axotomized DRG neurons (Michael and Priestley, 1999). The present study further supported these observations by measurements of TRPV 1 mRNA and protein using quantitative RT-PCR and Western blotting, respectively. The results indicated marked, significant, and permanent reductions in TRPV1 protein confirming the immunohistochemical analysis. TRPV1 mRNA expression was markedly reduced 3 and 14 days after nerve transection, but it showed a moderate increase after 30 days, which did not reach significance.

In sharp contrast, following perineural treatment with capsaicin, neurons in the L5 DRG exhibited distinct changes in TRPV1 mRNA and protein expression and TRPV1 immunostaining. Although the expression of TRPV1 mRNA in type C neurons was markedly decreased 3 days after the treatment, there was a clear-cut tendency toward recovery after 2 weeks, and a statistically significant recovery to about $60 \%$ 

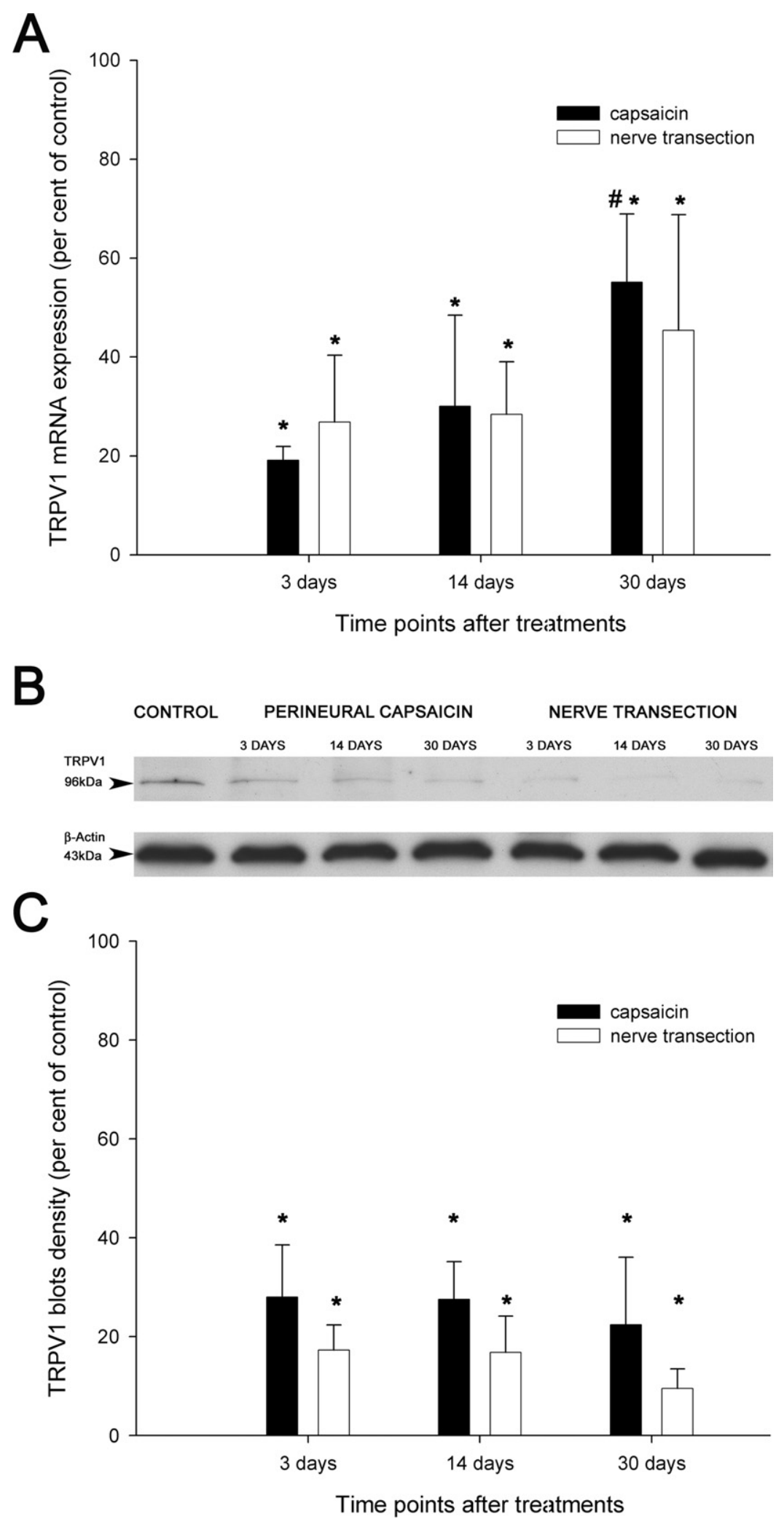

Fig. 2. Quantitative RT-PCR and Western blot analyses of the TRPV1 mRNA and protein expression. (A) Results of three to six independent experiments demonstrate the time course of changes in TRPV1 mRNA expression measured with quantitative RT-PCR in L5 DRGs following perineural capsaicin treatment and transection of the sciatic nerve. Note the marked time-dependent increase in TRPV1 mRNA expression following perineural capsaicin treatment. (B) Representative immunoblots of TRPV1 and $\beta$-actin proteins in L5 DRGs 3, 14, and $30 \mathrm{~d}$ after perineural capsaicin treatment and transection of sciatic nerve. (C) Results of three independent experiments demonstrate the time course of changes in TRPV1 protein. Note the marked decreases in the TRPV1 protein at all time points after perineural capsaicin treatment and nerve transection. * Significantly different from the control, $P<0.05$. " Significantly different from the 3-day value, $P<0.05$. 

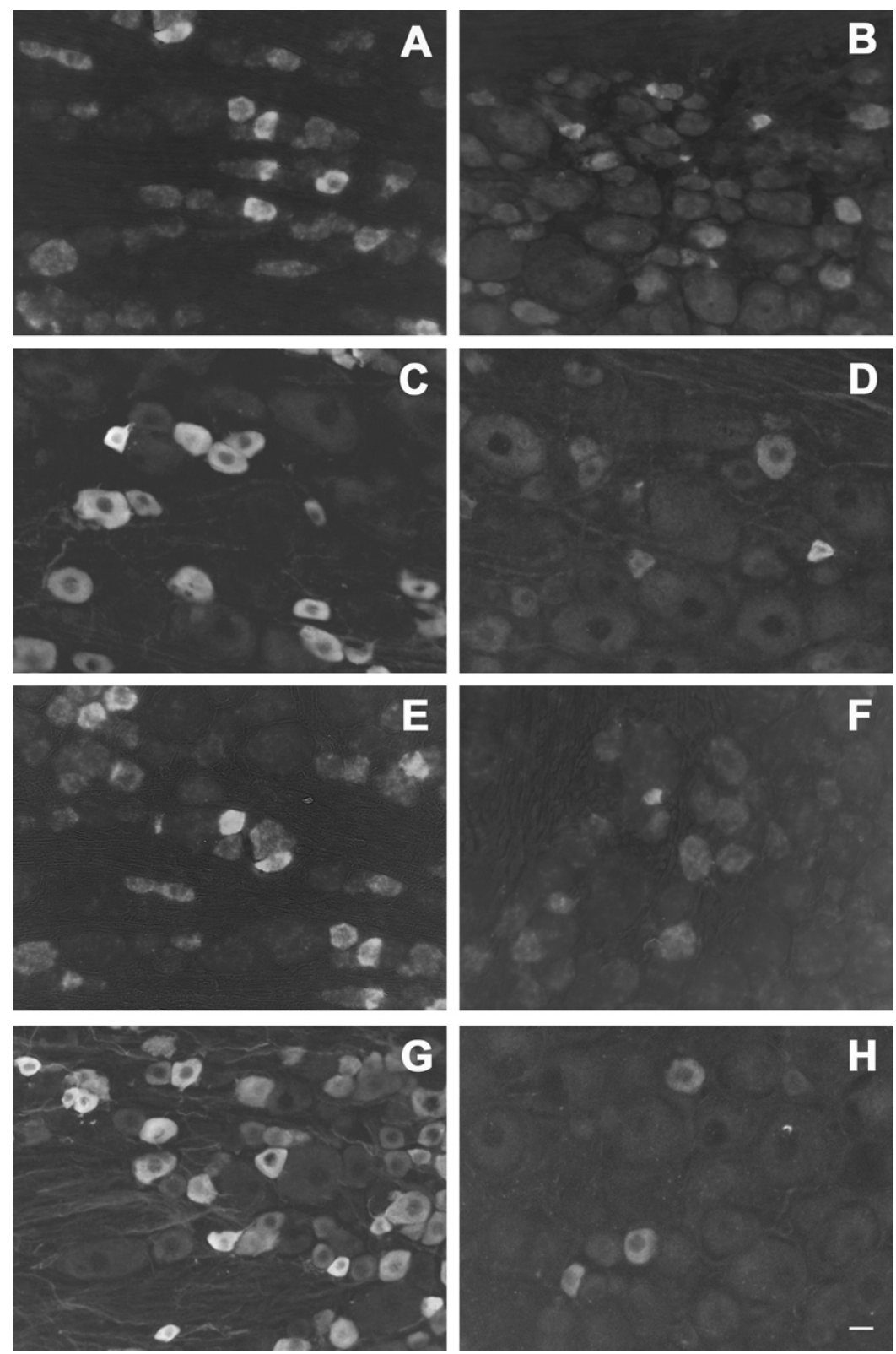

Fig. 3. Representative inverse microphotographs of the L5 DRGs, illustrating the effects of perineural capsaicin treatment (A-D) or sciatic nerve transection (E-H) on the TRPV1 mRNA expression (A, B and E, F) or TRPV1 immunoreactivity (C, D and G, H). Microphotographs illustrate the corresponding control $(A, C, E, G) D R G s$ and $D R G s$ ipsilateral to the sciatic nerve treated with capsaicin $(B, D)$ or peripheral nerve transection $(F, H)$ after $14 \mathrm{~d}$. Scale bar indicates $25 \mu \mathrm{m}$ and applies to all microphotographs.

of the control value was evident after a survival period of 4 weeks. In type B neurons, the TRPV1 mRNA expression already displayed a significant reduction by 3 days, with a significant recovery at the end of the study period. The measurements of total TRPV1 mRNA with quantitative RT-PCR in DRGs relating to the capsaicin-treated sciatic nerve confirmed these findings. An early profound decrease in TRPV1 mRNA expression was followed by a clear-cut tendency to recovery resulting in a significant increase in TRPV 1 mRNA expression to about $60 \%$ of the control at the end of the study. Interestingly, however, when the TRPV1 immunoreactivity was investigated, a tendency to recovery was not observed. The proportions of TRPV1-immunoreactive type C and type B DRG neurons decreased to about $12 \%$ and $25 \%$ of the total control neuronal population after 3 days and remained at these low levels even after a survival period of 4 weeks. It should be noted that these changes in the proportions of affected TRPV1 mRNAexpressing and TRPV1-immunoreactive neurons should be considered in light of the fact that about $20 \%$ of the neurons in the L5 DRGs are not affected by the lesions for their axons run in nerves other than the sciatic nerve (Yip et al., 1984; Aldskogius et al., 1988). These immunohistochemical findings were strongly supported by measurements of the 

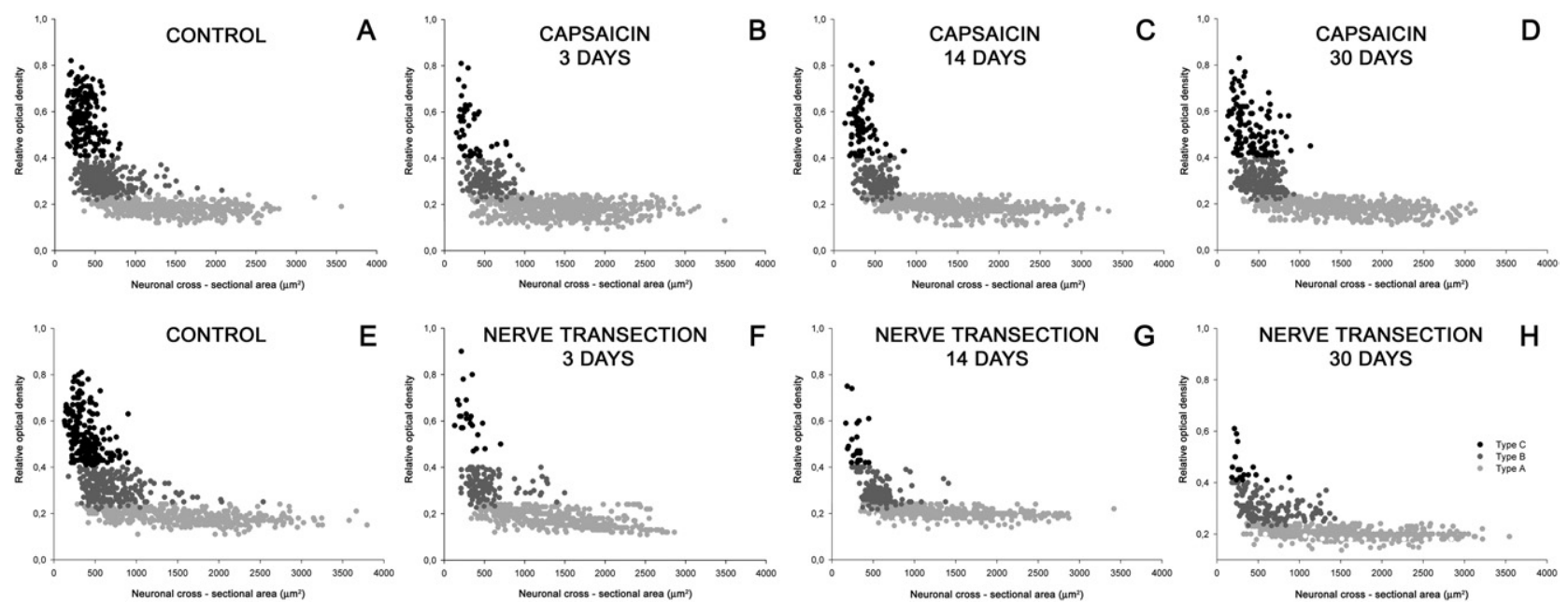

Fig. 4. Scatter plots showing the time course of changes in the populations of TRPV1 mRNA-expressing L5 DRG neurons following perineural capsaicin treatment $(A-D)$ and transection of the ipsilateral sciatic nerve $(E-H)$. Symbols of decreasing graytone intensities denote type $C, B$, and $A$ neurons, respectively.

TRPV1 protein with Western blotting of the L5 DRGs relating to the capsaicin-treated sciatic nerves. The TRPV1 protein was markedly decreased already 3 days after the capsaicin treatment and remained at that low level amounting about $30 \%$ of the control throughout the entire period of the study. The long-lasting, apparently irreversible functional impairments observed after perineural capsaicin treatment, such as the abolition of chemogenic pain and neurogenic inflammation, elevated latencies of thermal nociceptive reflexes, and reduced thermal hyperalgesia, are in accord with the downregulation of TRPV1 protein in the DRG neurons.

Several factors must be considered in the interpretation of the disparate changes brought about by the two types of nerve injuries, which differ substantially in their nature, that is, nerve transection and perineural capsaicin treatment. Nerve transection, classified as neurotmesis (Seddon, 1943), results in complete severance of the nerve. In con- trast, although leading to a selective chemodenervation of nociceptive afferents which express the TRPV1 by a mechanism which involves a slowly progressing dying-back type of degeneration process (Jancsó and Lawson, 1990; Jancsó, 1992), perineural treatment with capsaicin leaves the nerve fibers continuous. The exact nature of this denervation process is still unclear, but it has been demonstrated that, although practically all capsaicin-sensitive C-fiber afferents are functionally inactivated, only about half of this population undergo degeneration, the number of unmyelinated axons in capsaicin-treated nerves decreasing by only some $30 \%$ (Jancsó and Lawson, 1990; Pini et al., 1990; Jancsó, 1992). This may imply that after perineural capsaicin, unlike after nerve transection, the surviving axons may provide some trophic support for the chemically injured neurons, which may be sufficient to promote the transcription, but not the translation of TRPV1 mRNA. This assumption is supported by find-
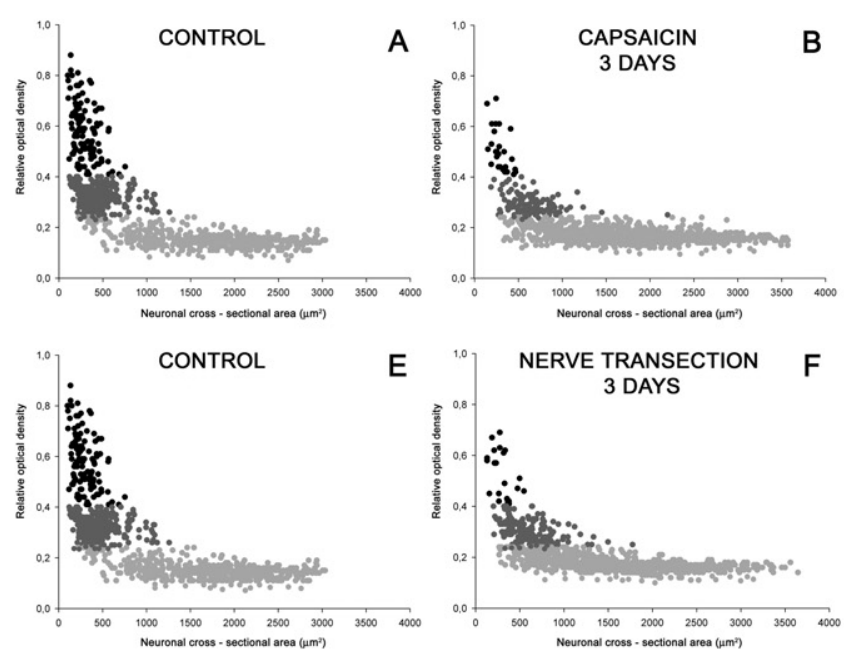
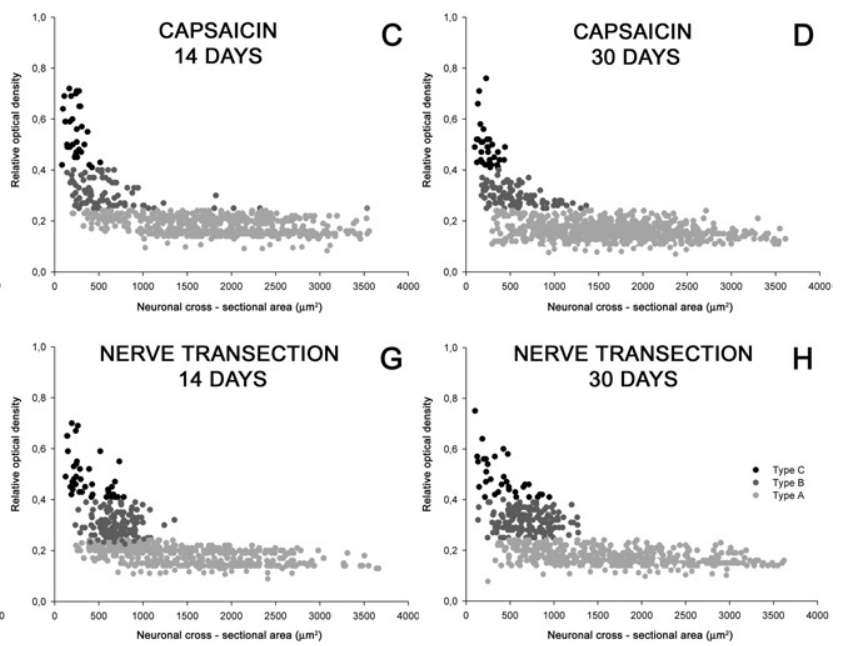

Fig. 5. Scatter plots showing the time course of changes in the populations of TRPV1-immunoreactive L5 DRG neurons following perineural capsaicin treatment $(A-D)$ and transection of the ipsilateral sciatic nerve $(E-H)$. Symbols of decreasing graytone intensities denote type $C$, B, and $A$ neurons, respectively. 
ings indicating that perineural capsaicin treatment exerts a profound selective, but transient blockade of axonal transport processes in C-fiber primary afferent neurons (Gamse et al., 1982; Sántha and Jancsó, 2003). Nerve growth factor (NGF) reaching the perikarya of the DRG neurons through retrograde axonal transport has been shown to play a pivotal role in the regulation of the expression of TRPV1 mRNA and protein in DRG neurons. Indeed, deprivation of DRG neurons of NGF under either in vivo or in vitro conditions has been shown to lead to a downregulation of TRPV1 mRNA expression and a loss of sensitivity to capsaicin (Winter et al., 1988; Aguayo and White, 1992; Jancsó and Ambrus, 1994; Jancsó et al., 1997; Michael and Priestley, 1999).

Similar phenomena involving a mismatch of mRNA and protein expressions have been reported, depending on the developmental and/or functional state of the DRG neurons. Peripherin mRNA and protein have been shown to be expressed in parallel in developing DRG neurons. However, in mature DRGs, large neurons express peripherin mRNA, but not the protein. This was attributed to changes in the availability of peripherally derived trophic factors such as NGF (Goldstein et al., 1996).

Although the distinct changes in the availability of trophic factors probably best explain, at least in part, the findings of the present study, other mechanisms may also be considered. The replacement of chemically injured neurons by proliferating DRG cells may offer an alternative possibility for the partial restitution of the neuron populations which express TRPV1 mRNA. Indeed, recent findings demonstrated a restoration of viscerosensory innervation by neurogenesis following a systemic injection of capsaicin (Czaja et al., 2008), which results in the degeneration of large populations of nodose and DRG neurons (Jancsó et al., 1977, 1980, 1985; Ritter and Dinh, 1988; Jancsó and Lawson, 1990; Jancsó, 1992; Hiura et al., 2002). However, this possibility seems unlikely, since little if any functional recovery was demonstrated after perineural treatment with capsaicin (Jancsó et al., 1980, 2011; Fitzgerald and Woolf, 1982; Jancsó and Lawson, 1990; Jancsó, 1992; Dux et al., 1999; Sántha and Jancsó, 2003).

The present study suggests that the regulation of the expression of TRPV1 after nerve injury is dependent on the type of the injury and not on the type of the DRG neuron. Whereas nerve transection resulted in an apparently long-lasting downregulation of TRPV1 mRNA expression, the selective chemodenervation of capsaicin-sensitive DRG neurons produced a transient and largely reversible downregulation of TRPV1 mRNA expression as shown by both in situ hybridization and quantitative RT-PCR. However, both treatments induced a seemingly irreversible inhibition of TRPV1 translation and/or changes in posttranslational processing, resulting in a massive and permanent loss of TRPV1 protein from DRG neurons, as assessed by immunohistochemistry and Western blotting following perineural capsaicin treatment or nerve transection. The present findings may have important implications as concerns the mechanism(s) of chemically induced selective analgesia. The results point to the possibility that interfering with the translation and/or post-translational processing of nociceptive ion channels, such as the TRPV1, by using specific siRNAs, for example, may offer a novel approach to the production of antinociception by employing molecular biological tools.

Acknowledgments-This work was supported in part by OTKA PD 73259, TAMOP 4.2.1/B-09/1/KONV-2010-0005, and TAMOP 4.2.2/B-10/1-2010-0012. The authors are grateful to Z. Ambrus and $E$. Hegyeshalmi for their expert technical assistance and $D$. Durham for linguistic correction of the article.

\section{REFERENCES}

Aguayo LG, White G (1992) Effects of nerve growth factor on TTX-and capsaicin-sensitivity in adult rat sensory neurons. Brain Res 570:61-67.

Aldskogius H, Wiesenfeld-Hallin Z, Kristensson K (1988) Selective neuronal destruction by ricinus-communis agglutinin-I and its use for the quantitative-determination of sciatic-nerve dorsal-root ganglion-cell numbers. Brain Res 461:215-220.

Armitage P (2001) Biostatistics in clinical trial. Chichester: John Whiley.

Armitage P, Colton T (2005) Encyclopedia of biostatistics. Chichester: John Wiley.

Baranowski R, Lynn B, Pini A (1986) The effects of locally applied capsaicin on conduction in cutaneous nerves in four mammalian species. Br J Pharmacol 89:267-276.

Caterina MJ, Julius D (2001) The vanilloid receptor: a molecular gateway to the pain pathway. Annu Rev Neurosci 24:487-517.

Caterina MJ, Leffler A, Malmberg AB, Martin WJ, Trafton J, PetersenZeitz KR, Koltzenburg M, Basbaum Al, Julius D (2000) Impaired nociception and pain sensation in mice lacking the capsaicin receptor. Science 288:306-313.

Caterina MJ, Schumacher MA, Tominaga M, Rosen TA, Levine JD, Julius D (1997) The capsaicin receptor: a heat-activated ion channel in the pain pathway. Nature 389:816-824.

Chung JM, Lee KH, Hori Y, Willis WD (1985) Effects of capsaicin applied to a peripheral nerve on the responses of primate spinothalamic tract cells. Brain Res 329:27-38.

Chung JM, Paik KS, Kim JS, Nam SC, Kim KJ, Oh UT, Hasegawa T, Chung K, Willis WD (1993) Chronic effects of topical application of capsaicin to the sciatic nerve on responses of primate spinothalamic neurons. Pain 53:311-321.

Czaja K, Burns GA, Ritter RC (2008) Capsaicin-induced neuronal death and proliferation of the primary sensory neurons located in the nodose ganglia of adult rats. Neuroscience 154:621-630.

Davis JB, Gray J, Gunthorpe MJ, Hatcher JP, Davey PT, Overend P Harries MH, Latcham J, Clapham C, Atkinson K, Hughes SA, Rance K, Grau E, Harper AJ, Pugh PL, Rogers DC, Bingham S, Randall A, Sheardown SA (2000) Vanilloid receptor-1 is essential for inflammatory thermal hyperalgesia. Nature 405:183-187.

Domoki F, Sántha P, Bari F, Jancsó G (2003) Perineural capsaicin treatment attenuates reactive hyperaemia in the rat skin. Neurosci Lett 341:127-130.

Donaldson LF, McQueen DS, Seckl JR (1995) Neuropeptide gene expression and capsaicin-sensitive primary afferents: maintenance and spread of adjuvant arthritis in the rat. J Physiol 486: 473-482.

Dux M, Sann H, Schemann M, Jancsó G (1999) Changes in fibre populations of the rat hairy skin after selective chemodenervation by capsaicin. Cell Tissue Res 296:471-477.

Fitzgerald M, Woolf CJ (1982) The time course and specificity of the changes in the behavioural and dorsal horn cell responses to noxious stimuli following peripheral nerve capsaicin treatment in the rat. Neuroscience 7:2051-2056.

Gamse R, Petsche U, Lembeck F, Jancsó G (1982) Capsaicin applied to peripheral nerve inhibits axoplasmic transport of substance $P$ and somatostatin. Brain Res 239:447-462. 
Gibson SJ, McGregor G, Bloom SR, Polak JM, Wall PD (1982) Local application of capsaicin to one sciatic nerve of the adult rat induces a marked depletion in the peptide content of the lumbar dorsal horn. Neuroscience 7:3153-3162.

Goldstein ME, Grant P, House SB, Henken DB, Gainer H (1996) Developmental regulation of two distinct neuronal phenotypes in rat dorsal root ganglia. Neuroscience 71:243-258.

Green EC (1968) Anatomy of the rat. New York: Hafner.

Hiura A, Nakae Y, Nakagawa $\mathrm{H}$ (2002) Cell death of primary afferent nerve cells in neonatal mice treated with capsaicin. Anat Sci Int 77:47-50.

Holzer P (1991) Capsaicin: cellular targets, mechanisms of action, and selectivity for thin sensory neurons. Pharmacol Rev 43:143-201.

Holzer P (2008) The pharmacological challenge to tame the transient receptor potential vanilloid-1 (TRPV1) nocisensor. $\mathrm{Br} \mathrm{J}$ Pharmacol 155:1145-1162.

Jancsó G (1992) Pathobiological reactions of C-fibre primary sensory neurones to peripheral nerve injury. Exp Physiol 77:405-431.

Jancsó G (2009) Neurogenic inflammation in health and disease. In: Neuroimmune biology, Vol. 8 (Bérczi I, Szentiványi A, eds)Amsterdam: Elsevier.

Jancsó G, Ambrus A (1994) Capsaicin sensitivity of primary sensory neurones and its regulation. In: Peripheral neurons in nociception: physio-pharmacological aspects, Vol. 1 (Besson JM et al., eds), pp 71-87. Paris: John Libbey Eurotext.

Jancsó G, Dux M, Oszlács O, Sántha P (2008) Activation of the transient receptor potential vanilloid-1 (TRPV1) channel opens the gate for pain relief. Br J Pharmacol 155:1139-1141.

Jancsó G, Juhász A, Dux M, Sántha P, Domoki F (1997) Axotomy prevents capsaicin-induced sensory ganglion cell degeneration. Primary Sensory Neuron 2:159-165.

Jancsó G, Király E (1980) Distribution of chemosensitive primary sensory afferents in the central nervous system of the rat. J Comp Neurol 190:781-792.

Jancsó G, Király E, Jancsó-Gábor A (1977) Pharmacologically induced selective degeneration of chemosensitive primary sensory neurones. Nature 270:741-743.

Jancsó G, Király E, Jancsó-Gábor A (1980) Direct evidence for an axonal site of action of capsaicin. Naunyn Schmiedebergs Arch Pharmacol 313:91-94

Jancsó G, Király E, Joó F, Such G, Nagy A (1985) Selective degeneration by capsaicin of a subpopulation of primary sensory neurons in the adult rat. Neurosci Lett 59:209-214.

Jancsó G, Lawson SN (1987) Perineural capsaicin treatment of the sciatic-nerve in adult-rats causes transganglionic changes in the spinal-cord dorsal horn. J Physiol 394:109-109.

Jancsó G, Lawson SN (1988) Ganglionic changes associated with transganglionic degeneration of capsaicin-sensitive primary sensory afferents-a quantitative morphometric and immunohistochemical study. Reg Peptides 22:97-97.

Jancsó G, Lawson SN (1990) Transganglionic degeneration of capsaicin-sensitive $\mathrm{C}$-fiber primary afferent terminals. Neuroscience 39:501-511.

Jancsó G, Oszlács O, Sántha P (2011) The capsaicin paradox: pain relief by an algesic agent. Anti-Inflammatory and Anti-Allergy Agents in Medicinal Chemistry 10:52-56.

Jancsó G, Such G (1983) Effects of capsaicin applied perineurally to the vagus nerve on cardiovascular and respiratory functions in the cat. J Physiol 341:359-370.

Jancsó G, Such G, Rödel C (1987) A new approach to selective regional analgesia. In: Trends in cluster headache (Sicuteri $F$, Vecchiet L, Fanciullacci M, eds), pp 59-68. Amsterdam, New York: Excerpta Medica.

Jancsó N (1968) Desensitization with capsaicin as a tool for studying the function of pain receptors. In: Pharmacology of pain (Lim RKS, ed), pp 33-55. Oxford: Pergamon Press.
Julius D, Basbaum Al (2001) Molecular mechanisms of nociception. Nature 413:203-210.

Kasama S, Kawakubo M, Suzuki T, Nishizawa T, Ishida A, Nakayama $\mathrm{J}$ (2007) RNA interference-mediated knock-down of transient receptor potential vanilloid 1 prevents forepaw inflammatory hyperalgesia in rat. Eur J Neurosci 25:2956-2963.

Kissin I, Bright CA, Bradley EL Jr. (2002) Selective and long-lasting neural blockade with resiniferatoxin prevents inflammatory pain hypersensitivity. Anesth Analg 94:1253-1258.

Kissin I, Freitas CF, Mulhern HL, DeGirolami U (2007) Sciatic nerve block with resiniferatoxin: an electron microscopic study of unmyelinated fibers in the rat. Anesth Analg 105:825-831.

Knotkova H, Pappagallo M, Szállási A (2008) Capsaicin (TRPV1 agonist) therapy for pain relief: farewell or revival? Clin J Pain 24:142-154.

Lowry OH, Rosebrough NJ, Farr AL, Randall RJ (1951) Protein measurement with the Folin phenol reagent. J Biol Chem 193:265-275.

Maggi CA, Meli A (1988) The sensory-efferent function of capsaicinsensitive sensory neurons. Gen Pharmacol 19:1-43.

Maniatis T, Fritsch EF, Sambrook J (1982) Molecular cloning: a laboratory manual. NY: Cold Spring Harbor Laboratory.

Michael GJ, Priestley JV (1999) Differential expression of the mRNA for the vanilloid receptor subtype 1 in cells of the adult rat dorsal root and nodose ganglia and its downregulation by axotomy. J Neurosci 19:1844-1854.

Nagy JI, Hunt SP (1983) The termination of primary afferents within the rat dorsal horn: evidence for rearrangement following capsaicin treatment. J Comp Neurol 218:145-158.

Oszlács O, Sántha P, Jancsó G (2009) Long-lasting antinociceptive and anti-inflammatory effects of $\mathrm{N}$-oleoyldopamine, an endogenous vanilloid. Neuropeptides 43:413-413.

Pfaffl MW (2001) A new mathematical model for relative quantification in real-time RT-PCR. Nucleic Acids Res 29: e45.

Pini A, Baranowski R, Lynn B (1990) Long-term reduction in the number of $\mathrm{C}$-fibre nociceptors following capsaicin treatment of a cutaneous nerve in adult rats. Eur J Neurosci 2:89-97.

Pospisilova E, Palecek J (2006) Post-operative pain behavior in rats is reduced after single high-concentration capsaicin application. Pain 125:233-243.

Ritter S, Dinh TT (1988) Capsaicin-induced neuronal degeneration: silver impregnation of cell bodies, axons, and terminals in the central nervous system of the adult rat. J Comp Neurol 271:79-90.

Sántha P, Jancsó G (2003) Transganglionic transport of choleragenoid by capsaicin-sensitive C-fibre afferents to the substantia gelatinosa of the spinal dorsal horn after peripheral nerve section. Neuroscience 116:621-627.

Seddon HJ (1943) Three types of nerve injury. Brain 66:237-246.

Tohda C, Sasaki M, Konemura T, Sasamura T, Itoh M, Kuraishi $Y$ (2001) Axonal transport of VR1 capsaicin receptor mRNA in primary afferents and its participation in inflammation-induced increase in capsaicin sensitivity. J Neurochem 76:1628-1635.

Tominaga M, Caterina MJ, Malmberg AB, Rosen TA, Gilbert H, Skinner K, Raumann BE, Basbaum Al, Julius D (1998) The cloned capsaicin receptor integrates multiple pain-producing stimuli. Neuron 21:531-543.

Welk E, Petsche U, Fleischer E, Handwerker HO (1983) Altered excitability of afferent $\mathrm{C}$-fibres of the rat distal to a nerve site exposed to capsaicin. Neurosci Lett 38:245-250.

Winter J, Forbes CA, Sternberg J, Lindsay RM (1988) Nerve growth factor (NGF) regulates adult rat cultured dorsal root ganglion neuron responses to the excitotoxin capsaicin. Neuron 1:973-981.

Yip HK, Rich KM, Lampe PA, Johnson EM (1984) The effects of nerve growth-factor and its antiserum on the postnatal-development and survival after injury of sensory neurons in rat dorsal-root ganglia. J Neurosci 4:2986-2992. 